\title{
Zooartesanatos de pescados e seus subprodutos comercializados em Santarém (PA)
}

No município de Santarém (PA), é comercializada uma grande quantidade de artesanatos utilizando animais aquáticos como matéria-prima. Essa arte é denominada zooartesanato. O presente trabalho apresenta a identificação das espécies de pescados utilizados e comercializados em feiras artesanais e seu enquadramento na lista vermelha de espécies ameaçadas de acordo com a IUNC (União Internacional para a Conservação da Natureza e dos Recursos Naturais). As coletas dos principais pescados e seus subprodutos comercializados como artesanatos foram realizados em duas feiras artesanais: Terminal Fluvial de Santarém e Cristo Rei, e três lojas de Santarém, e em seis lojas artesanais na vila balneária de Alter-do-Chão, sendo classificadas como utilitárias, figurativas e zoológicas. Foram registradas 27 espécies de animais aquáticos, sendo que o número de espécies mais representativas se enquadra no Filo Mollusca (Classe Bivalvia e Gastropoda), com um total de 14 espécies identificadas. O Filo Chordata (Classe Actinopterygii) obteve um total de 12 espécies, e Filo Arthropoda (Classe Malacostraca) foi registrado somente um exemplar. De acordo com as categorias da lista vermelha da IUNC, a maioria das espécies consta como não identificadas (NE), entretanto a Lutjanus analis (CUVIER, 1828) está enquadrada na categoria quase ameaçada (NT). Constatou-se que muitas espécies aquáticas são utilizadas na fabricação de zooartesanato, e vale ressaltar que essa é uma atividade exploratória, gerando impactos à fauna aquática regional.

Palavras-chave: Artesanato; Comércio de fauna; Fauna aquática; Identificação.

\section{Zooartesanatos de pescados and their by-products marketed in Santarém (PA)}

\begin{abstract}
In the municipality of Santarém (PA), a large amount of crafts is marketed using aquatic animals as raw material. This art is called zooartesanato. This paper presents the identification of fish species used and marketed in artisanal fairs and their inclusion in the red list of endangered species according to the IUNC (International Union for the Conservation of Nature and Natural Resources). The collections of the main fish and their by-products marketed as handicrafts were carried out at two craft fairs: Santarém River Terminal and Cristo Rei, and three Santarém stores, and six craft stores in the seaside resort of Alter-do-Chão, being classified as utilitarian, figurative and zoological. Twenty-seven species of aquatic animals were recorded, and the number of most representative species is in the Mollusca Phylum (Class Bivalvia and Gastropoda), with a total of 14 identified species. Phylum Chordata (Class Actinopterygii) obtained a total of 12 species, and Phylum Arthropoda (Class Malacostraca) was recorded only one specimen. According to the IUNC red list categories, most species are unidentified (NE), however Lutjanus analyze (CUVIER, 1828) falls into the near threatened category (NT). It was found that many aquatic species are used in the manufacture of zooartesanato, and it is noteworthy that this is an exploratory activity, generating impacts to the regional aquatic fauna.
\end{abstract}

Keywords: Crafts; Wildlife trade; Aquatic fauna; Identification

Topic: Uso Sustentável da Biodiversidade

Reviewed anonymously in the process of blind peer.
Received: 12/08/2018

Approved: 18/08/2018
Taciane Lemos Andrade

Universidade Federal do Oeste Pará, Brasil http://lattes.cnpq.br/4013885890346405 tacyanne.drade@gmail.com

Yago Estouco Rodrigues (iD

Universidade Federal do Oeste do Pará, Brasi http://lattes.cnpq.br/9560286132041078

http://orcid.org/0000-0002-9143-946X estoucoyago@gmail.com

Ildson de Souza Tenório (D)

Universidade Federal do Oeste do Pará, Brasi http://lattes.cnpq.br/6616074900416909 http://orcid.org/0000-0001-6783-3187 ildsonstenorio@gmail.com

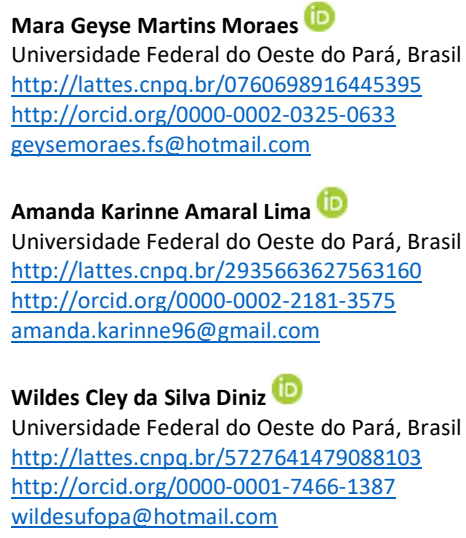
http://lattes.cnpq.br/0760698916445395 http://orcid.org/0000-0002-0325-0633 geysemoraes.fs@hotmail.com

Amanda Karinne Amaral Lima (iv)

Universidade Federal do Oeste do Pará, Brasil http://lattes.cnpq.br/2935663627563160 http://orcid.org/0000-0002-2181-3575 amanda.karinne96@gmail.com

Wildes Cley da Silva Diniz (it)

Universidade Federal do Oeste do Pará, Brasil http://lattes.cnpq.br/5727641479088103 http://orcid.org/0000-0001-7466-1387 wildesufopa@hotmail.com

José Max Barbosa Oliveira Junior (iD Universidade Federal do Oeste do Pará, Brasil http://lattes.cnpq.br/1353014365045558 http://orcid.org/0000-0002-0689-205X maxbio@hotmail.com

\section{Referencing this:}

ANDRADE, T. L.; RODRIGUES, Y. E.; TENÓRIO, I. S.; MORAES, M. G. M.; LIMA, A. K. A.; DINIZ, W. C. S.; OLIVEIRA JUNIOR, J. M. B.

Zooartesanatos de pescados e seus subprodutos comercializados em Santarém (PA). Revista Ibero-Americana de Ciências Ambientais, v.9, n.6, p.120-132, 2018. DOI: http://doi.org/10.6008/CBPC21796858.2018.006.0014

DOI: 10.6008/CBPC2179-6858.2018.006.0014 


\section{INTRODUÇÃO}

A produção dos primeiros artesanatos data do período neolítico (COSTA, 2012), onde o homem começava a desenvolver objetos para atender suas necessidades, transformando pedras, ossos, fibras de vegetais e cerâmicas em utensílios e adornos. No Brasil, o artesanato já era produzido pelos índios antes da chegada dos portugueses, sendo que eles confeccionavam cocares, cestos, colares e cerâmicas. A diversidade cultural no Brasil é representada pela dança, fauna, flora, comidas típicas, vestuários, religiosidade, pelo folclore e também através da arte e do artesanato dentre outras coisas (TROMBONI, 2009).

Artesão pode ser definido como aquele indivíduo que fabrica peças utilizando matéria-prima local ou regional e não utiliza um molde repetitivo para confecção do artesanato (VAINSENCHER, 2006). Já o artesanato é classificado como sendo qualquer produto doméstico comercializado e fabricado de maneira manual, podendo utilizar ferramentas simples e algumas máquinas rudimentares, utilizando matéria-prima local ou regional, fabricado por um ou mais artesãos podendo esses participar de associações ou cooperativas (VAINSENCHER, 2006). Para Tedesco (2006), o artesanato é uma atividade transmitida de pai para filho, acompanhando a evolução dos desenvolvimentos socioeconômicos e culturais.

No Pará, são utilizados para confecção de artesanatos, produtos extraídos da própria região, sendo eles, fibras, barro, palha, pedras, variados tipos de sementes, argila, peixes e escamas de algumas espécies de peixe também são utilizadas para fabricação dessa arte. $O$ termo zooartesanato é dado a todo e qualquer objeto fabricado através de animais ou partes de animais (ALVES et al., 2006), e essa atividade consiste na utilização de penas, ossos, dentes, pele ou o próprio animal inteiro para confecção de objetos decorativos, utilitários, brincos, anéis, cordões, chaveiros, etc., evidenciando os traços culturais da região representados pela diversidade de objetos, cores, formas e representações.

Nas grandes cidades paraenses, como Belém, Santarém, entre outras, há artesãos profissionais especializados em zooartesanato produzindo objetos voltados para economia turística, por possuírem uma diversidade de paisagens naturais que atraem uma grande quantidade de turistas para a região. A produção do zooartesanato é uma opção na geração de empregos, sendo uma atividade importante para a economia local dessas cidades através do turismo (SOUZA et al., 2014).

O Brasil possui uma grande riqueza de diversidade de fauna aquática, principalmente a de peixes, havendo um elevado número de espécies (BUCKUP et al., 2007). Essa grande quantidade de espécies resulta pela presença de amplos sistemas hidrográficos (MACHADO et al., 2010), como a bacia hidrográfica Amazônica, do São Francisco, entre outras, onde a bacia Amazônica é a mais rica com aproximadamente 1400 espécies (REIS et al., 2003).

Animais aquáticos marinhos ou de ambientes dulciaquícolas são muito utilizados para a fabricação de zooartesanatos, tanto o animal inteiro como parte destes em outras peças. O turista é o principal consumidor, e tem interesse em adquirir um souvenier que retrate a natureza local (ALVES et al., 2010). Os peixes constituem uma importante fonte de alimento para o homem, sendo considerado como um alimento saudável. Vários produtos podem ser feitos a partir dos peixes, utilizando partes que, muitas vezes, não são comestíveis, como espinhas, couro e escamas. A utilização desses derivados diminui a geração de resíduos e 
gera renda para os artesãos (COSTA, 2016).

Assim como os peixes, os moluscos de ambientes dulciaquícolas e marinho compõe um grupo bastante utilizado como matéria prima para a confecção de zooartesanato. Isso se deve ao fato de os moluscos possuírem valvas de calcário, popularmente chamado de conchas, para revestimento de seu corpo mole, e estas possuírem formatos variados e possuírem uma beleza única. Moluscos bivalves produzem o nácar (material orgânico brilhante) (DEBACHER et al., 2010), também conhecido como madrepérola muito utilizado na fabricação de botões.

Os moluscos são capturados casualmente ou encomendados para a produção de cordões, colares, cortinas, entre outras (TENÓRIO et al., 2002, citado por ALVES, 2010). Alves et al. (2010) comenta que essas conchas são capturadas de forma expressiva e a baixo custo financeiro, e que na maioria das vezes, estão vazias quando capturadas. Entretanto, podem ser encontrados com o animal vivo, sendo que as partes moles são descartadas, comercializando somente sua concha. Muitas espécies bivalves utilizadas no zooartesanato são capturadas no mar ou oriunda de descarte proveniente de outra atividade, sendo que dessa forma reduz os impactos a fauna aquática (SILVA et al., 2007).

O presente trabalho tem como objetivo identificar espécies de pescados e subprodutos utilizados para fabricação de zooartesanato comercializados em feiras artesanais de Santarém e Alter-do-Chão (PA). O presente levantamento pode auxiliar na identificação dos espécimes utilizados na produção de zooartesanato no município de Santarém (PA), e o enquadramento da prática na lista vermelha de espécies ameaçadas de acordo com a IUNC (União Internacional para a Conservação da Natureza e dos Recursos Naturais), já que a prática do zooartesanato consiste em atividade que implica na utilização da biodiversidade.

\section{MATERIAIS E MÉTODOS}

\section{Área de estudo}

O estudo foi desenvolvido no município de Santarém (PA), cuja extensão total de sua área é de 17.898.389km² (IBGE, 2015), e em um de seus distritos (Alter-do-Chão). Santarém situa-se no oeste do estado do Pará, Brasil, e compreende as coordenadas de latitude $02^{\circ} 26^{\prime} 22^{\prime \prime}$ S e longitude $54^{\circ} 41^{\prime} 55^{\prime \prime} \mathrm{W}$. A precipitação pluviométrica é um pouco mais elevada, em média de $1.920 \mathrm{~mm} / \mathrm{ano}$, temperatura média anual de $25^{\circ} \mathrm{C}$ e a umidade relativa do ar de $86 \%$ (NEPSTAD et al., 2002). Santarém situa-se à margem direita do Rio Tapajós e seu principal curso d'água tem extensão de $132 \mathrm{~km}$. Segundo dados do IBGE, a população estimada em 2016 é de 294.447 habitantes, conforme se vê na figura 1.

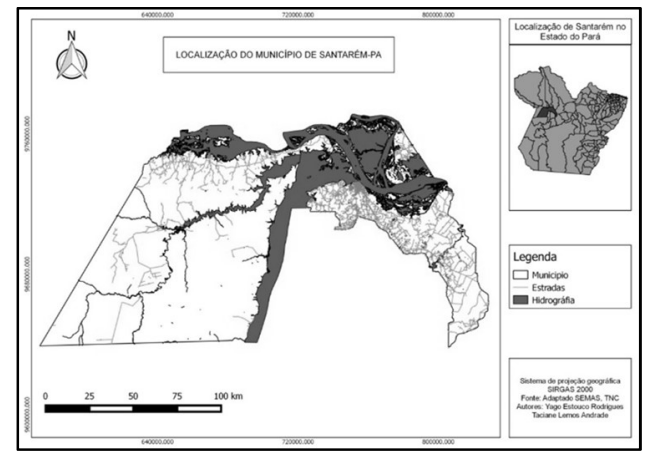

Figura 1: Localização do Município de Santarém (PA). 


\section{Coleta de dados}

Utilizou-se a pesquisa-descritiva para apresentar os tipos de pescados utilizados na confecção de zooartesanatos que ao ponto de vista da natureza, a pesquisa pode ser classificada como básica, pois segundo Prodanov et al. (2013), "[...] objetiva gerar informações úteis para o avanço da ciência sem aplicação prática prevista". Em relação ao ponto de vista da forma de abordagem do problema, a pesquisa se classifica como básica quantitativa na visão de Prodanov et al. (2013), pois “[...] considera que tudo pode ser quantificável, o que significa traduzir em números opiniões e informações para classificá-las e analisá-las. Requer o uso de recursos e de técnicas estatísticas (percentagem, média, moda, mediana, desvio-padrão, coeficiente de correlação, análise de regressão etc.)".

O estudo em questão é considerado quantitativo, pois quantifica os artesanatos e a forma como são classificados. Do ponto de vista da forma de coleta de dados, foram utilizados para este estudo os procedimentos de levantamento, entrevista, observação, pesquisa de campo e pesquisa bibliográfica. A pesquisa de campo consiste na observação de fatos e fenômenos na coleta de dados a eles referentes e em registros relevantes posteriormente analisados (MARCONI et al., 2003). A entrevista é uma conversa informal entre duas pessoas, no intuito de obter informações importantes do entrevistado através de perguntas formuladas pelo entrevistador. Utilizou-se também o procedimento de levantamento de dados, onde Gil (2010) conceitua da seguinte forma:

As pesquisas deste tipo caracterizam-se pela interrogação direta das pessoas cujo comportamento se deseja conhecerem. Basicamente, procede-se à solicitação de informações a um grupo significativo de pessoas acerca do problema estudado para, em seguida, mediante análise quantitativa, obterem-se as conclusões correspondentes aos dados coletados.

A observação sempre deve ser utilizada juntamente com outra técnica de pesquisa, pois, do ponto de vista científico, essa técnica possui vantagens e limitações que podem ser administradas com o uso concorrente de outras técnicas de pesquisa (MARCONI et al., 1996). Utilizou-se essa técnica no estudo para observar quais artesanatos possuíam partes ou animais inteiros no âmbito da pesquisa.

O estudo foi realizado no período de novembro 2016 a fevereiro de 2017. As coletas dos principais pescados e seus subprodutos comercializados como artesanatos foram realizados em: duas feiras artesanais (Terminal Fluvial de Santarém e Cristo Rei), três lojas de Santarém e seis lojas artesanais na vila balneária de Alter-do-Chão. As lojas em questão assinaram um termo de consentimento livre e esclarecido com termo de confidencialidade, portanto mantem-se sigilo em relação aos seus respectivos nomes. Esses são pontos tradicionais de venda de artesanato em Santarém e Alter-do-Chão, devido ao grande fluxo de turistas que circulam nesses locais.

A identificação das peças de artesanato deu-se através de conversas informais com artesãos locais, donos de comércios, vendedores e alguns turistas. As peças de artesanato oriundas de qualquer pescado (marinho ou de água doce) ou seu subproduto, disponíveis para venda, foram contabilizadas em cada estabelecimento comercial e, sempre que possível, a matéria-prima animal utilizada para a confecção foi identificada no próprio local, por se tratar de espécies bastante conhecidas na região. Algumas peças, quando necessário, foram adquiridas para identificação dos animais até a mais inclusiva categoria taxonômica 
possível, com auxílio de especialistas.

\section{Análise dos dados}

As peças foram classificadas em três categorias: utilitário, figurativo e peças zoológicas. As peças utilizadas para uso doméstico ou para o uso pessoal foi classificado como utilitário; o figurativo, são as peças utilizadas para decoração; e quando o próprio animal, inteiro ou parte dele é vendido como uma peça decorativa, sem que possua adornos inseridos nele, é classificado como peça zoológica (ALVES et al., 2006). Classificou-se em subproduto todo objeto confeccionado com peças convencionais ou com adornos de partes de animais.

As espécies utilizadas como zooartesanto foram categorizadas segundo os critérios da IUNC. Os critérios da lista vermelha têm como objetivos fornecer informações sobre o estado das espécies no mundo; dar ênfase a biodiversidade ameaçada; repassar informações para orientação de conservação da biodiversidade.

Os zooartesanatos foram catalogados de acordo com a variedade de material utilizados para sua fabricação (ossos, escamas, dentes, na íntegra), e não por unidade de peça encontrada. Aa quantificação das peças artesanais deu-se através da listagem de peças que utilizavam partes de animais e em quantas lojas encontrou-se essas peças. Utilizaram-se gráficos de informação principalmente por proporcionar um fácil entendimento através de uma visualização rápida e clara e são classificados como gráficos de distribuição de frequência por valores, no formato de colunas ou barras múltiplas no intuito de melhorar o entendimento das variáveis quantitativas, essas variáveis geralmente assumem como valores números (GUIMARÃES, 2008).

\section{RESULTADOS}

Os artesanatos de peixes e/ou seus subprodutos são oriundos em sua maioria de água doce $(43,1 \%)$, já os moluscos $(36,2 \%)$ e crustáceo (2\%) provêm principalmente de ambientes de água salgada, conforme ilustrado pela figura 2. Conforme os relatos dos vendedores e donos das lojas, foram observados que os chaveiros e imãs para geladeira fabricados a partir das escamas de pirarucu possuem maior número de vendas entre todas as peças artesanais encontradas em Santarém. Encontrou-se um total de 86 peças artesanais nas 11 lojas visitadas, das quais 51 são provenientes de Santarém e 35 de Alter-do-Chão (quadro 1).

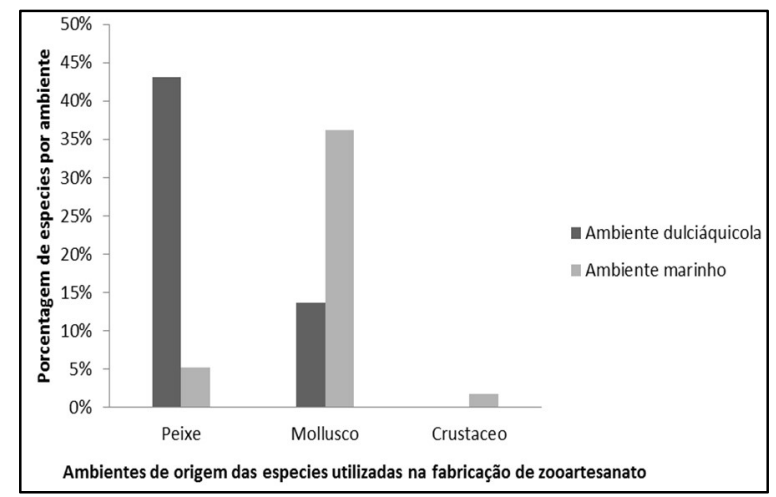

Figura 2: Porcentagem de Zooartesanatos por tipo de ambiente (dulciáquicola e marinho) amostrados em Santarém e Alter-do-Chão (PA). 
Quadro 1: Levantamento de zooartesanato e seus subprodutos encontrados em Santarém e Alter-do-Chão.

\begin{tabular}{|c|c|c|c|}
\hline \multirow{2}{*}{ GRUPOS } & \multirow{2}{*}{ ARTESANATO } & \multicolumn{2}{|c|}{ PRESENTE/AUSENTE } \\
\hline & & Santarém & Alter-do-Chão \\
\hline \multirow{28}{*}{ Peixe } & Tucunaré empalhado & 1 & 1 \\
\hline & Piranha Empalhada & 1 & 1 \\
\hline & Tamuatá empalhado & 1 & 1 \\
\hline & Aruanã empalhado & 1 & 1 \\
\hline & Cujuba empalhada & 1 & 1 \\
\hline & Acari empalhado & 1 & 1 \\
\hline & Chaveiro feito com piranha empalhada & 1 & 1 \\
\hline & Imã de geladeira utilizando piranha & 1 & 1 \\
\hline & Acari utilizado como adorno de zarabatana & 1 & 1 \\
\hline & Ossos de tambaqui como adorno de máscaras indígenas & 1 & 1 \\
\hline & Dentes de piranha utilizados como adorno de mascaras & 1 & 1 \\
\hline & Esporão de Cujuba como adorno de decoração & 1 & 1 \\
\hline & Chaveiro feito com esporão de Cujuba & 1 & 0 \\
\hline & Escama de Aruanã para fabricação de cortina & 1 & 0 \\
\hline & Brinco fabricado com escama de pirarucu & 1 & 1 \\
\hline & Chaveiro fabricado com escama de pirarucu & 1 & 0 \\
\hline & Pingente fabricado com escama de pirarucu & 1 & 0 \\
\hline & Imã de geladeira pintado fabricado com escama de pirarucu & 1 & 1 \\
\hline & Lustre fabricado com escama de pirarucu & 1 & 0 \\
\hline & Apanhador de sonhos fabricado com escama de pirarucu & 1 & 0 \\
\hline & Lixa Natural de unha fabricado com escama de pirarucu & 1 & 0 \\
\hline & Adorno de garrafas fabricado com escama de pirarucu & 1 & 0 \\
\hline & Adorno de zarabatanas fabricado com escama de pirarucu & 1 & 0 \\
\hline & Adorno de máscaras indígenas fabricado com escama de pirarucu & 1 & 0 \\
\hline & Flores utilizando escama de pescada & 0 & 1 \\
\hline & Flores utilizando escama de cioba & 0 & 1 \\
\hline & Arranhadeira utilizando dentes de Cachorra & 0 & 1 \\
\hline & Adorno de canetas fabricado com escama de pirarucu & 1 & 0 \\
\hline \multirow{29}{*}{ MOLUSCOS } & Cortina & 1 & 1 \\
\hline & Colar & 1 & 1 \\
\hline & Pingente & 1 & 1 \\
\hline & Apito & 0 & 1 \\
\hline & Chaveiro & 1 & 1 \\
\hline & Apanhador de sonhos & 1 & 0 \\
\hline & Tartaruga (caracol e concha marinha) & 1 & 0 \\
\hline & Galo feito de conchas marinhas & 1 & 0 \\
\hline & Caracol utilizado como decoração & 1 & 0 \\
\hline & Coruja (concha e caracol) & 1 & 0 \\
\hline & Adorno de garrafas (ostras) & 1 & 0 \\
\hline & Chaveiro (ostras) & 1 & 0 \\
\hline & Brinco (ostra) & 1 & 0 \\
\hline & Brinco (concha) & 1 & 1 \\
\hline & Pulseira (concha) & 1 & 1 \\
\hline & Chaveiro madrepérola & 1 & 1 \\
\hline & Colar madrepérola & 1 & 1 \\
\hline & Pingente madrepérola & 1 & 1 \\
\hline & Pulseira madrepérola & 1 & 1 \\
\hline & Porta moeda madrepérola & 1 & 1 \\
\hline & Decorações diversas: madrepérola & 1 & 1 \\
\hline & Anel conchas & 0 & 1 \\
\hline & Anel madrepérola & 0 & 1 \\
\hline & Anel abalone & 0 & 1 \\
\hline & Decoração natural madrepérola & 1 & 0 \\
\hline & Pulseira abalone & 1 & 1 \\
\hline & Colar abalone & 1 & 1 \\
\hline & Pingente abalone & 1 & 0 \\
\hline & Decoração diversa com formatos de animais utilizando abalone & 1 & 0 \\
\hline CRUSTÁCEO & Caranguejo empalhado & 1 & 0 \\
\hline
\end{tabular}

Desse total, os artesanatos foram mais representativos em Santarém, onde o maior número de 
zooartesanato é fabricado com a utilização de peixes na íntegra ou partes deles (49\%), e os objetos confeccionados com a utilização de molusco totalizam $49 \%$ dos produtos encontrados e crustáceo com a menor porcentagem (2\%). Em Alter-do-chão observa-se que a percentagem das peças fabricadas com peixes inteiros ou parte deles é de $37 \%$, enquanto as peças utilizando moluscos totalizam $63 \%$, não foi evidenciada nenhuma peça utilizando crustáceo (figura 3).

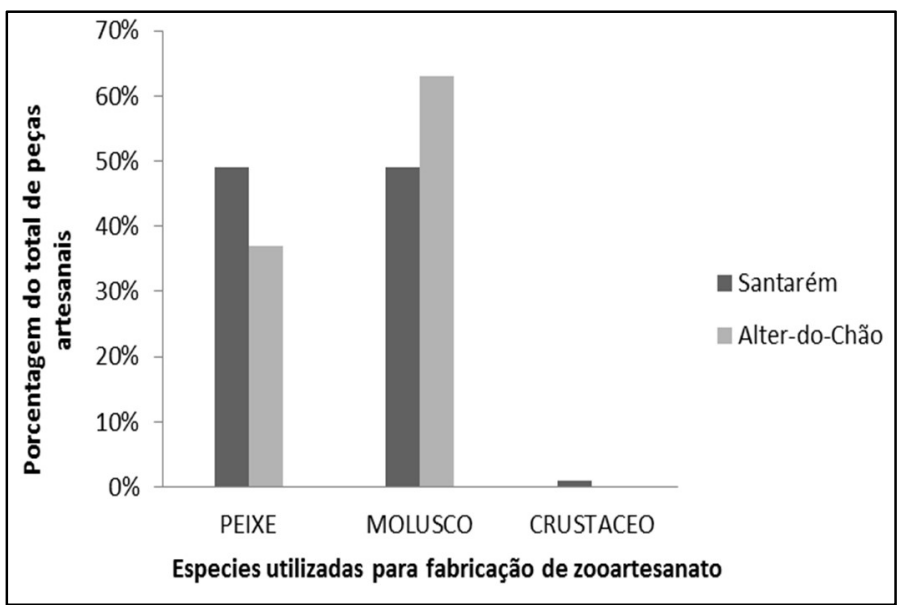

Figura 3: Porcentagem de peças oriundas de peixes, moluscos e crustáceo encontradas em Santarém e Alter-do-Chão (PA)

Dos zooartesanatos disponíveis para comercialização nas 11 lojas visitadas nos dois locais estudados foram registradas 27 espécies de animais aquáticos, sendo que o número de espécies mais representativa se enquadra no Filo Mollusca (Classe Bivalvia e Gastropoda) com um total de 14 espécies identificadas. O Filo Chordata (Classe Actinopterygii) obteve um total de 12 espécies; Filo Arthropoda (Classe Malacostraca) foi registrado somente um exemplar (quadro 2). Percebe-se que a maioria das espécies consta como não identificadas (NE), de acordo com as categorias da lista vermelha da IUCN, e que diz que as espécies não foram submetidas aos critérios de avaliação de risco (quadro 2).

As espécies Arapaima gigas e Prisodon obliquus se enquadram na categoria dados deficientes ou insuficientes (DD). Isso indica que não se têm informações especificas para avaliar se a espécie corre risco de extinção. Essa categoria não pode validar o grau de risco da espécie, porém mostra que ainda são necessárias informações precisas para uma avaliação adequada (quadro 2).

A Lutjanus analis é uma espécie de peixe marinho conhecido como cioba e está enquadrada na categoria quase ameaçada (NT), pelos critérios de classificação provavelmente será incluída numa das categorias de ameaça: Vulnerável, Em Perigo ou Criticamente em Perigo. O termo ameaça na Lista Vermelha significa que a espécie se enquadra em um dos critérios acima descritos, porém não indica que a espécie está quase em extinção. Ressalta-se que as espécies Neritina virginea e Castalia ambigua estão enquadradas na categoria seguro ou pouco preocupante (LC), esta categoria demonstra que a espécie não sofre risco de extinção e é a categoria de risco mais baixo (quadro 2).

Quadro 2: Espécies de animais aquáticos utilizadas na fabricação de zooartesanatos e sua classificação nas categorias da Lista Vermelha da IUCN distribuídas no município de Santarém e Alter-do-chão.

\begin{tabular}{|c|c|c|c|c|}
\hline FILO & CLASSE & NOME CIENTíFICO & NOME POPULAR & CATEGORIAS IUCN \\
\hline Arthropoda & Malacostraca & Ucides cordatus (Linnaeus, 1763) & CARANGUEIJO & NE \\
\hline Chordata & Actinopterygii & Pterygoplichthys pardalis (Castelnau, 1855) & ACARI & NE \\
\hline
\end{tabular}




\begin{tabular}{|c|c|c|c|c|}
\hline & & Osteoglossum bicirrhosum (Cuvier, 1829) & ARUANÃ & $\mathrm{NE}$ \\
\hline & & Lutjanus analis (G. Cuvier, 1828) & CIOBA & NT \\
\hline & & Pterodoras granulosus (Valenciennes, 1821) & CUJUBA & $\mathrm{NE}$ \\
\hline & & Hydrolycus scomberoides (Cuvier, 1819) & CACHORRA & $\mathrm{NE}$ \\
\hline & & Cymoscion spp. & PESCADA & $\mathrm{NE}$ \\
\hline & & Pygocentrus nattereri (Kner, 1858) & PIRANHA-VERMELHA & $\mathrm{NE}$ \\
\hline & & Serrasalmus sp. & PIRANHA & $\mathrm{NE}$ \\
\hline & & Arapaima gigas (Schinz, 1822) & PIRARUCU & DD \\
\hline & & Colossoma macropomum (Cuvier, 1816) & TAMBAQUI & $\mathrm{NE}$ \\
\hline & & Hoplosternum littorale (Hancock, 1828) & TAMUATÁ & $\mathrm{NE}$ \\
\hline & & Cichla spp. & TUCUNARE & $\mathrm{NE}$ \\
\hline \multirow{14}{*}{ Mollusca } & \multirow{9}{*}{ Bivalvia } & Anomalocardia brasiliana (Gmelin, 1791) & CONCHA & $\mathrm{NE}$ \\
\hline & & Anadara ovalis (Bruguiere, 1789) & CONCHA & $\mathrm{NE}$ \\
\hline & & Iphigenia brasiliana (Lamarck, 1818) & OSTRA & $\mathrm{NE}$ \\
\hline & & Noetia bisulcata (Lamarck, 1819) & CONCHA & $\mathrm{NE}$ \\
\hline & & Tivela mactroides (Born, 1778) & MARISCO- DE-AREIA & $\mathrm{NE}$ \\
\hline & & Trachycardium muricatum (Linnaeus, 1758) & CONCHA & $\mathrm{NE}$ \\
\hline & & Castalia ambigua (Lamarck, 1819) & MEXILHÃO & LC \\
\hline & & Prisodon obliquus (Schumacher, 1817) & MEXILHÃO & $\mathrm{DD}$ \\
\hline & & Triplodon corrugatus (Lamarck, 1819) & MEXILHÃO & $\mathrm{NE}$ \\
\hline & \multirow{5}{*}{ Gastropoda } & Haliotis iris (Gmelin, 1791) & ABALONE & $\mathrm{NE}$ \\
\hline & & Strombus sp. & CONCHA & $\mathrm{NE}$ \\
\hline & & Cypraea acicularis (Gmelin, 1791) & BUZIO & $\mathrm{NE}$ \\
\hline & & Neritina virginea (Linnaeus, 1758) & ARUÁ-DO-MANGUE & $\mathrm{LC}$ \\
\hline & & Olivella sp. & CONCHA & $\mathrm{NE}$ \\
\hline
\end{tabular}

Legenda: Segura ou pouco preocupante ou Least Concern, em inglês (LC); Quase ameaçada ou Near Threatened, em inglês (NT); Vulnerável ou Vulnerable (VU); Em perigo ou Endangered (EN); Criticamente em Perigo ou Em Perigo Crítico ou Critically Endangered (CR); Extinta na natureza ou Extinct in the Wild (EW); Extinta ou Extinct, em inglês (EX); Dados Insuficientes ou Data Deficient (DD); e Não avaliada ou Not Evaluated (NE).

As peças utilitárias totalizaram $32 \%$ das peças encontradas nas lojas, enquanto as peças figurativas correspondem $18 \%$ do total. Algumas das peças listadas possuem mais de um tipo de utilização, as peças zoológica-figurativas correspondem a $38 \%$ dos tipos de objetos encontrados, sendo elas feitas com animais inteiros empalhados e utilizados como decoração. As peças utilitária-zoológicas correspondem a $6 \%$ do total de peças encontradas. E por último também totalizando $6 \%$ das peças classificadas estão as peças figurativoutilitárias. Em Alter-do-Chão 43\% do total das peças encontradas nas lojas foram peças utilitárias, enquanto as peças figurativas, zoológicas-figurativas e utilitárias-zoológicas correspondem ambas a $19 \%$ do total das peças e não foi encontrada nenhuma peça figurativa-utilitária no balneário de Alter-do-Chão (figura 4).

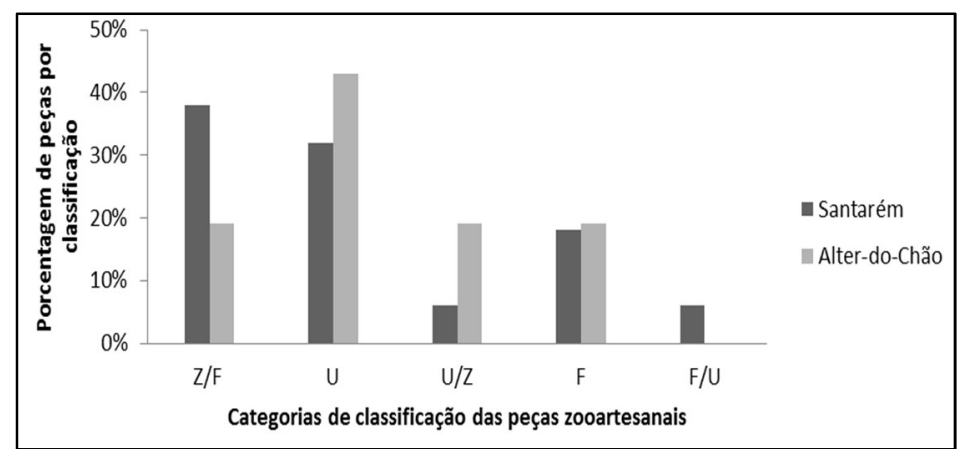

Figura 4: Classificação das peças zooartesanais encontradas nas lojas de Santarém e Alter-do-Chão, correspondente a sua utilização. Legenda: Z/F: Zoológica/Figurativa; U: Utilitária; U/Z: Utilitária/Zoológica; F: Figurativa; F/U: Figurativa/Utilitária.

Observa-se que as peças de zooartesanatos mais representativas em Santarém são as Zoológicas/Figurativas representadas por peixes empalhados, conchas na integras utilizada na fabricação de 
chaveiros, imãs de geladeira. Em Alter-do-Chão, a mais expressiva representatividade de peças foi a Utilitária sendo representada por anéis, brincos, pulseiras, colares, arranhadeira cortinas, porta-moedas e enfeites em geral.

A peça artesanal mais peculiar, encontrada em uma das lojas de Alter-do-Chão, é uma Arranhadeira ou coçador, fabricado com os dentes do peixe Cachorra e também se enquadra como peça utilitária (figura 5A). Nota-se que o serrilhado no topo do coçador é os dentes do animal. A madrepérola (figura 5B) quando beneficiada eleva o valor de suas peças possibilitando aos artesãos um rendimento maior valorizando o produto final.
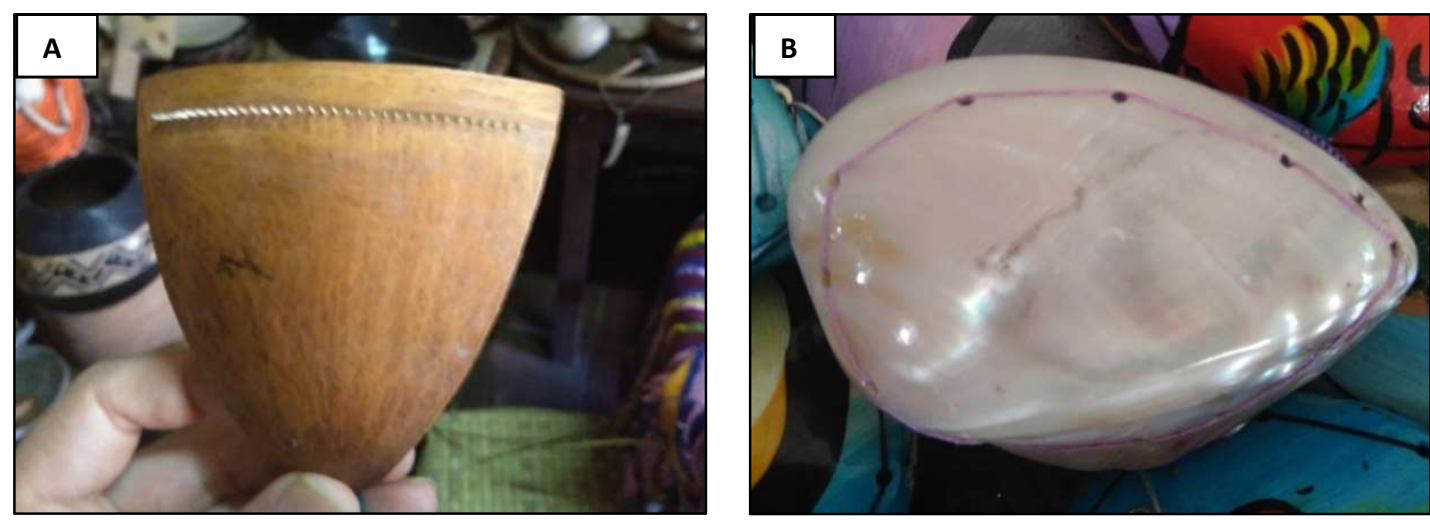

Figura 5: A) Coçador utilizando dentes de peixe cachorra; B) porta moedas fabricado utilizando uma ostra de madrepérola na integra encontradas em uma das lojas de Alter-do-Chão (PA).

A figura 6 demonstra que o artesanato utiliza matéria prima que expressa algo da cultura de sua região, entre os zooartesanatos encontrados pode-se observar que algumas peças carregam consigo a herança histórica das tribos tapajônicas. Observa-se que em relação ao ambiente, o artesanato proveniente de peixes de água doce é maior do que o artesanato oriundo de peixes marinhos, isso ocorre pelo fato de Santarém possuir o porto pesqueiro mais importante do Médio amazonas e estar localizada na confluência dos Rios Amazonas e Tapajós (ISSAC et al., 1996), com uma diversidade abundante de peixes que são utilizados como matéria prima pelos artesãos locais.

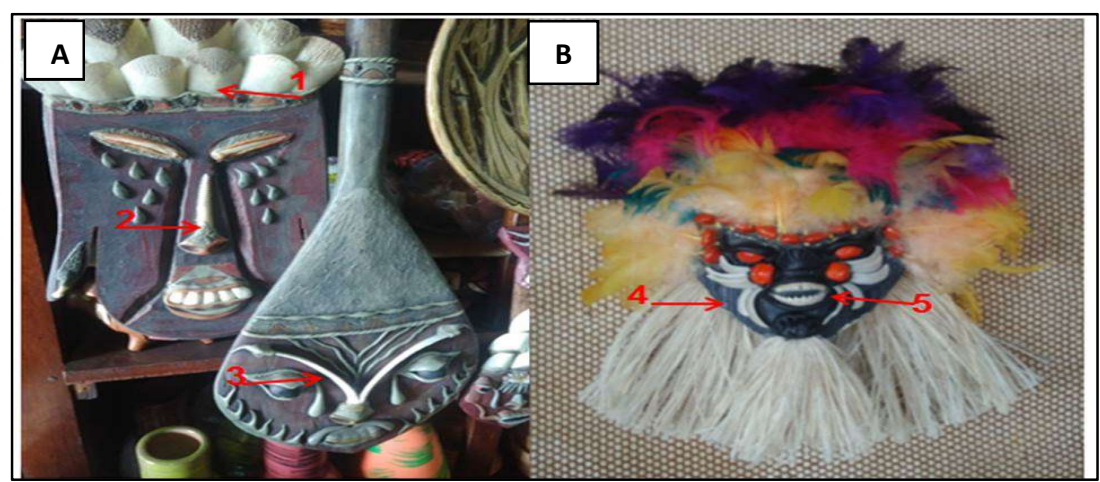

Figura 6: Artigos indígenas: A) Máscara utilizando como adorno: (1) Escama de pirarucu, (2) Esporão de Cujuba; Remo contendo (3) Ossos de tambaqui e B) Mascara contendo (4) Ossos de tambaqui; (5) Dente de piranha.

Costa (2016) ressalta que o pescado é visto como alimento, porém, todo resíduo proveniente desse pescado pode ser considerado matéria prima podendo ser reutilizado integralmente, incluindo seu couro e escamas. Foi constatado que existem peças feitas a partir das escamas de Arapaima gigas (pirarucu), cerca 
de 11 tipos de objetos são produzidos com a utilização das escamas desse peixe, sendo utilizadas separadas ou como adorno de peças maiores.

A Instrução Normativa Ibama, 끈, de 18 de junho de 2014, no seu art. 2o, proíbe, anualmente, a captura, a comercialização e o transporte do pirarucu (Arapaima gigas), conforme se tem: I - nos estados do Amazonas, Pará, Acre e Amapá, no período de 10 de dezembro a 31 de maio, exceto os espécimes oriundos de piscicultura devidamente registrado e autorizado pelo IBAMA/AM (BRASIL, 1998). Por esse motivo o Arapaima gigas (pirarucu) não pode ser vendido na íntegra empalhado como no caso de outras espécies encontradas, mas suas escamas são usadas com frequência na fabricação de produtos.

Os artigos artesanais com o uso de animais têm crescido gradativamente aumentando a sua procura, estes produtos possuem ótima aceitação no comércio em ambos locais e o beneficiamento das conchas e das escamas de peixes oferece um resultado satisfatório, pois não atribui às peças nenhum tipo de odor (SILVA et al., 2007).

A representatividade de artigos confeccionados com moluscos e crustáceos são maiores no ambiente marinho, principalmente porque muitos artigos são importados de regiões litorâneas como do Nordeste Brasileiro, segundo a Secretaria Estadual de Turismo do Espirito Santo, Piúma é uma das principais cidades brasileiras na fabricação de artesanatos originados de conchas de moluscos.

Estima-se que no Brasil existem cerca de 150 espécies de moluscos bivalves de água doce (SIMONE, 2006). O conhecimento sobre a quantidade de espécies de moluscos dulciaquícolas na região amazônica não é satisfatório (PIMPÃO, 2016). Contudo no estado do Pará a captura de moluscos bivalves é uma tradição não somente de moradores litorâneos como também de águas interiores, a captura desses moluscos auxilia no aumento da renda familiar após o beneficiamento e retirada da madrepérola contida nas valvas (conchas) dessas ostras sendo posteriormente transformadas em artesanato e biojóias (SOARES, 2016).

A prática de catação de conchas em praias é comum por todo Brasil e a comercialização de conchas de moluscos em mercados públicos, feiras livres, feiras típicas de artesanato, facilita a confecção de artesanatos utilizando esse material (ALVES et al., 2006). No estado do Pará foi criado o Programa de Desenvolvimento da Coleta Produtiva de Moluscos como incentivo aos artesãos e pescadores regionais diante do potencial apresentado. As peças não só reproduzem a cultura de um povo como também valoriza o artesanato deixando um diferencial único restaurando os traços de objetos produzidos há muito tempo no intuito de transformá-las em referências oficiais da cultura santarena.

A preocupação com o aumento da demanda turística na região nordeste, pois eleva a procura por artesanatos regionais (ALVES et al., 2007), essa realidade não é diferente na região norte, o que leva a uma maior exploração das espécies utilizadas para fabricação de zooartesanato. Algumas peças foram produzidas com escamas de peixes (dulciaquícolas e marinhos), as escamas possuem baixo custo e é pouco explorada pela comunidade científica, além de se um material relativamente abundante (SOUZA, 2013). Os zooartesanatos elaborados com a utilização de escama de peixe foram brincos, imãs de geladeiras, chaveiros, apanhador de sonhos, cortinas, sendo utilizada para adornar várias outras peças, porém a peça mais interessante fabricada com escamas de peixes foram arranjos de flores. 
A confecção dessas peças é muito simples utilizando apenas cola quente e papel (COSTA, 2016), enquanto a Secretaria de Turismo do Espírito Santo comenta que a pratica deve ser minuciosa requerendo muito cuidado e capricho, porém o resultado final gera uma peça de aparência delicada com extrema resistência e de grande durabilidade.

Conforme um estudo publicado por Alves et al. (2006), sobre um levantamento de animais aquáticos na produção de zooartesanato, a espécie Ucides cordatus e Arapaima gigas encontra-se incluída como sobreexplotada na Lista Nacional das Espécies de Invertebrados Aquáticos e Peixes em Extinção do IBAMA, na Instrução Normativa n-5 de 21 de maio de 2004.

Outros materiais são usados na fabricação dos zooartesanatos como colas, parafusos, epóxi, tinta, sementes, entre outros, auxiliam no acabamento das peças (ALVES et al., 2006). O artesanato é importante para o crescimento turístico, no estado do Pará existe uma riqueza de produtos artesanais e possui grande influência indígena (PARÁ, 2017) abrangendo o número de peças artesanais que na sua maioria retrata essa cultura indígena tão representativa na região.

Um exemplo de zooartesanato utilitário bem vendido na região devido a essa cultura, são os Muiraquitãs esculpidos em formas de sapo, eram usados pelas mulheres tapajós como amuleto para prevenir doenças e evitar a infertilidade, são lindas peças presenteáveis, foram encontrados alguns modelos esculpidos em madrepérola.

Além da cultura indígena, outras peças artesanais procuradas pelos turistas através da cultura regional são os peixes empalhados, essas peças demonstram a variedade biologia de espécies na região e são enquadradas como peças Zoológicas-Figurativas, pois além se serem confeccionadas com a taxidermização do animal inteiro a peça é vendida com suvenir de decoração.

\section{CONCLUSÕES}

Observa-se que muitas espécies aquáticas utilizadas na fabricação de zooartesanato são de origem marinha oriundas da Região Nordeste do país. Portanto, muitas espécies encontradas não são nativas da região Amazônica. Vale ressaltar que os exemplares de espécies regionais utilizados para fabricação de zooartesanato são produzidos com a captura manual dos mesmos e fabricados por artesões locais, sendo essa uma atividade na maioria das vezes, exploratória e não se tem muito conhecimento dos impactos gerados à fauna regional ou período sazonal que essas espécies são coletadas.

A pesquisa em questão evidência que a espécie Arapaima gigas possuiu períodos anuais de proibição na sua captura, porém após seu período de defeso a espécie e seus derivados (ossos, escamas, couro) podem ser comercializados legalmente mediante nota fiscal. $\mathrm{O}$ artigo auxilia na verificação de espécimes utilizados na produção dessa arte com maior frequência, já que não se têm muitos estudos realizados na região nesse âmbito e pode contribuir em análises quantitativas nos tipos de implicações a biodiversidade aquática local com embasamento nesse estudo preliminar. Para tal, serão necessários estudos mais aprofundados no assunto, considerando que no presente estudo foram observadas peças artesanais com a utilização de espécies ameaçadas de extinção. 


\section{REFERÊNCIAS}

ALVES, M. S.; SILVA, M. A.; MELO JÚNIOR, M.; PINTO, S. L.. Zooartesanato comercializado em Recife, Pernambuco, Brasil. Revista Brasileira de Zoociências, Juiz de Fora, v.8, n.2, p.99-109, 2006.

ALVES, M. S.; SILVA, M. A.; PINTO, S. L.. Perfil socioeconômico dos atores envolvidos na produção e comercialização de zooartesanato em Recife, PE - Brasil. Revista Nordestina de Zoologia, Pernambuco, v.4. n.1. p.97-104, 2010.

BRASIL. Instrução Normativa Ibama n.34 de 18 de junho de 2004. Estabelece normas gerais para o exercício da pesca do pirarucu. Brasília: DOU, 2004.

BRASIL. Instrução Normativa MMA no 05 de 21 de maio de 2004. Reconhece como espécies ameaçadas de extinção espécies sobreexplotadas ou ameaçadas de sobreexplotação. Brasília: DOU, 2004.

BRASIL. Lei Federal n.9605 de 12 de fevereiro de 1998. Dispõe sobre as sanções penais e administrativas derivadas de condutas e atividades lesivas ao meio ambiente, e dá outras providências. Brasília: DOU, 1998.

BUCKUP, P. A.; MENEZES, N. A.; GHAZZI, M. S.. Catálogo das espécies de peixes de água doce do Brasil. Rio de Janeiro: UFRJ, 2007.

COSTA, L. M.. Artesanato como forma de manifestação cultural e complementação de renda: um estudo de caso associação comunitária do bairro do Lambari. Monografia (Especialização em Gestão de Projetos Culturais e Organização de Eventos - Universidade de São Paulo, São Paulo, 2012.

COSTA, W. M.; VIDAL, J. M. A.; VEIGA, M. C. M.; RODRIGUES, J. M.; SANTOS, J. F.. Aproveitamento de resíduos de pescado: o artesanato com escamas de peixe. Revista Ciências em Extensão, São Paulo, v.12, n.2, p.8-17, 2016.

DEBACHER, N. A.; SILVA, D.; CASTILHOS JUNIOR, A. B.; ROHER, F.. Caracterização físico-química e microestrutural de conchas de moluscos bivalves provenientes de cultivos da região litorânea da Ilha de Santa Catarina. Química Nova, Florianópolis, v.33, n.5, p.1053-1058, 2010. DOI: http://doi.org/10.1590/S0100-40422010000500009

GIL, A. C.. Como Elaborar Projetos de Pesquisa. 5 ed. São Paulo: Atlas, 2010.

GUIMARÃES, P. R. B.. Métodos quantitativos estatísticos. Curitiba: IESDE Brasil S. A., 2008.

IBGE. Instituto Brasileiro de Geografia e Estatística. Cidades: Santarém: população e ambiente. IBGE: 2017.

ISSAC, V. J.; MILSTEIN, A.; RUFFINO, M. L.. A pesca artesanal no Baixo Amazonas: análise multivariada da captura por espécies, Revista Acta Amazônica, Manaus, v.26, p.185-208, 1996.

MACHADO, A. B. M.; DRUMOND, G. M.; PAGLIA, A. P.. Livro Vermelho da Fauna Brasileira Ameaçada de Extinção. 2 ed. Brasília: MMA, 2010.

MARCONI, M. A; LAKATOS, E. M.. Fundamentos da metodologia científica. 5 ed. São Paulo: Atlas, 2003. MARCONI, M. A; LAKATOS, E. M.. Técnicas de pesquisa: planejamento e execução de pesquisas, amostragens e técnicas de pesquisas, elaboração e interpretação de dados. 3 ed. São Paulo: Atlas, 1996.

NEPSTAD, D. C.; MOUTINHO, P. R. S.; DIAS-FILHO, M. B.; DAVIDSON, E. ; CARDINOT, G.; MARKEWITZ, D.; FIGUEIREDO, R.; VIANNA, N.; LEFEBVRE, P.; RAY, D.; SILVA, J. M.; CARDOSO, L.; STERNBERG, M.; MOREIRA, J. B.; GUERREIRO, L.; BARROS, F. Y.; ISHIDA, E.; BELK, E. K.. The effects of rainfall exclusion on canopy processes and biogeochemistry of an Amazon forest. Journal of Geophysical Research, v.107, n.20, p.80-85, 2002. DOI: https://doi.org/10.1029/2001JD000360

PARÁ. Artesanato. Belém: DOE, 2017.

PIMPÃO D. M.. Diversidade biológica e sociocultural do Baixo Rio Negro, Amazônia Central. Manaus: UEA, 2009.

PRODANOV, C. C; FREITAS, E. C.. Metodologia do trabalho científico: métodos e técnicas da pesquisa e do trabalho acadêmico. 2 ed. Porto Alegre: Feevale, 2013.

REIS, R. E.; KULLANDER, S. O.; FERRARIS, C. J. J.. Check list of the freshwater fishes of South and Central America. Porto Alegre: EDPUCRS, 2003.

SILVA, A. F.; DIAS, T.; COSTA, A.; SANTOS, R.; BEZERRA, A. R.. Zooartesanato comercializado na costa da Paraíba (Nordeste do Brasil): Implicações Ecológicas e Conservacionistas. In: CONGRESSO DE ECOLOGIA DO BRASIL. Anais. Caxambu: SEB, 2007.

SILVA, A. P. G.; SANTOS, J. F.; COSTA, W. M.; VIDAL, J. M. A. Processamento de escamas para confecção de peças artesanais. In: CONGRESSO BRASILEIRO DE ENGENHARIA DE PESCA, 17. Anais. Belém: FAEP, 2011.

SIMONE, L. R. L.. Land and freshwater molluscs of Brazil. São Paulo: FAPESP, 2006.

SOARES, S. J.; DUARTE, L. C.; ROLDO, L.; SILVA, F. P.. Design de superfície em madrepérola: efeito degradê por gravação a laser. Revista Educação Gráfica, Bauru, v.20, n.1, p.40-51. 2016.

SOUSA, M. D. B.; CHAGAS, R. A.; FARIAS, L. C. F.; BARROS, M. R. F.; HERRMANN, M.. Gastrópodes utilizados no zooartesanato do município de Belém, Pará. In: SEMINÁRIO ANUAL DE INICIAÇÃO CIENTÍFICA DA UFRA, 12. Anais. Belém: UFRA, 2014.

SOUZA, J. C.; SILVA, A. P. G.; SANTOS, D. N.; COSTA, W. M.; BRITO, A. M. S. S.; VIDAL, J. M. A.; NASCIMENTO, E. C. L.. Avaliação espectroscópica e quimiométrica de escamas de tilápias submetidas a diferentes tipos de lavagem para aplicação no artesanato. In: JORNADA DE ENSINO, PESQUISA E EXTENSÃO, 13. Anais. Recife: UFRPE, 2013.

TEDESCO, J. C.. O artesanato como expressão de um sistema de autarquia econômico-familiar no meio rural: subsídios para uma história econômica regional. Revista Teoria e Evidência Econômica, Passo Fundo, v.14, n.30, 2006. 
TROMBONI, F.. O artesanato e a sua importância na economia e na cultura brasileira. Vinhedo: WebArtigos, 2009.
VAINSENCHER, S. A.. Artesanato do Nordeste do Brasil. Recife: FJN, 2007.

A CBPC - Companhia Brasileira de Produção Científica (CNPJ: 11.221.422/0001-03) detém os direitos materiais desta publicação. Os direitos referem-se à publicação do trabalho em qualquer parte do mundo, incluindo os direitos às renovações, expansões e disseminações da contribuição, bem como outros direitos subsidiários. Todos os trabalhos publicados eletronicamente poderão posteriormente ser publicados em coletâneas impressas sob coordenação da Sustenere Publishing, da Companhia Brasileira de Produção Científica e seus parceiros autorizados. Os (as) autores (as) preservam os direitos autorais, mas não têm permissão para a publicação da contribuição em outro meio, impresso ou digital, em português ou em tradução. 